malignant disease has been found in animals treated with cyclophosphamide.

In patients treated with cyclophosphamide symptoms referrable to the urinary tract may be severe and life-threatening. An acute transient cystitis which recovers when the drug is discontinued is the commonest feature and this is often associated with severe haematuria, dysuria, and increased frequency. Patients may, however, have no symptoms at all in spite of appreciable fibrosis and contraction of the bladder wall. Thus disease of the bladder is an important complication of cyclophosphamide therapy, and should when cyclosphosphamide is used in non-malignant conditions be taken into account as well as the recognized possibility of increasing the incidence of malignant disease. Since animal studies have suggested that the complication may be prevented by diuresis, it is a wise precaution to ensure that patients are adequately hydrated.

'Clayson, D. B., and E. H. Cooper, Advances in Cancer Research, 1970, 13,

' Philips, F. S., Sternberg, S. S., Cronin, A. P., and Vidal, P. M., Cancer Research, 1961, 21, 1577 .

Koss, L. G., Laboratory Investigation, 1967, 16, 44.

- Chaves, E., Revue Francaise d'Etudes Cliniques et Biologiques, 1968, 13, 56 5 Forni, A. M., Koss, L. G., Geller, W., Cancer, (Philadelphia), 1966, 96, 313. - Rubin, J. S., and Rubin, R. T., Fournal of Urology, 1966, 96, 313.

Johnson, W. W., and Meadows, D. C., New England fournal of Medicine, $1971,284,290$.

\section{Ileus and Pseudo-obstruction}

The gut's propulsive activity nearly always ceases for a time after abdominal operations. This is probably more the result of reflux inhibition, mediated by the splanchnic nerves, than a true paralysis, for it can be prevented experimentally by cutting those nerves. ${ }^{1}$ Intestinal activity usually returns a few hours after the operation has been completed, but gastric motility takes considerably longer to return, thus accounting for the delay before feeding by mouth becomes possible. ${ }^{23}$

Occasionally, as J. Neely and B. N. Catchpole have recently emphasized, ${ }^{4}$ a more severe disturbance supervenes, with distension of the gut by gas or fluid and with complete constipation. The factors which mediate the change from the simple physiological inactivity after operation to the second condition of apparent paralysis are ill-understood. Distension of the gut by itself is sufficient to reduce blood flow to the intestinal wall, 5 and theoretically a self-perpetuating pattern of distension leading to reduced blood flow followed in turn by reduced motor activity in the ischaemic bowel leading to further distension is easy to recognize. Nervous inhibition may also be an important mediator of this condition.

The well-established forms of treatment include the regimen of intravenous drip and gastric suction, special care being taken to correct potassium depletion. The removal of swallowed air by gastric suction is important in preventing further gaseous distension. Since there is no physical obstruction, various pharmacological methods of stimulating propulsive activity have been tried, such as the administration of cathartics, but without success. A more fruitful approach has been to encourage parasympathetic motor activity by the administration of drugs which either prevent the destruction of acetylcholine by cholinesterase, such as neostigmine, or are cholinergic agents, such as bethanecol, which has the advantage that it lacks the nicotinic side effects of carbachol. Neely and Catchpole emphasize the meed to exclude obstruc- tion as a cause of the patient's symptoms and illustrate the value of the pharmacological approach by reference to three patients in whom peristaltic activity was promptly restored after intravenous infusions of guanethidine combined with bethanecol or neostigmine, or of phentolamine and neostigmine. Two of these patients had had abdominal operations, one for appendicitis and the other for obstruction due to an ileal band. The third, a woman of 72 , developed apparent obstruction six days after the insertion of a h:p joint prosthesis, but was shown radiographically to have gas in all parts of the gastrointestinal tract.

This syndrome of pseudo-obstruction, as particularly exemplified by the third patient, has been well described. 67 It tends to develop in elderly patients and is frequently associated with an acute infection such as pneumonia or with cardiac or renal failure. Clinically it needs to be distinguished not only from organic internal obstruction but, for instance, from the apparent acute obstruction which often develops in association with acute pancreatitis or cholecystitis. Other potential sources of confusion include ischaemic disease of the gut, porphyria, lead poisoning, and intestinal amyloidosis. ${ }^{8} \mathrm{~A}$ further curious variety of chronic pseudo-obstruction has also been reported in association with steatorrhoea. 9

It is therefore possible to recognize separate groups of chronic and acute pseudo-obstruction and to divide the latter into varieties associated with localized intra-abdominal disease and with more generalized disease. A particularly helpful diagnostic feature is the presence of gas throughout the small and large intestine. Detection of it should always cause hesitation before undertaking laparotomy on an apparently obstructed patient.

\footnotetext{
1 Bayliss, W. M., and Starling, E. H., fournal of Phvsiology, 1899, 24, 99 Wells, C., Rawlinson, K., Tinckler, L., Jones, H., and Saunders, J., Lancet, 1961, 2, 136.

3 Rothnie, N. G., Harper, R. A. K., and Catchpole, B. N., Lancet, 1963, 2, 64.

Neely, J., and Catchpole, B. N., British fournal of Surgery, 1971, 58, 21.

5 Jacobson, E. D., Brobmann, G. F., and Brecher, G. A., Gastroenterology, $1970,58,575$

Stephens, F. O., British Medical fournal, 1962, 1, 1248.

Dudley, H. A. F., Sinclair, I. S. R., McLaren, I. F., McNair, T. J., and Newsam, I. E., Fournal of the Royal College of Surgeons of Edinburgh, 1958, 3, 206.

Legge, D. A., Wollaeger, E. E., and Carlson, H. C., Gut, 1970, 11, 764

Naish, J. M., Capper, W. M., and Brown, N. J., Gut, 1960, 1, 62.
}

\section{Radiation Hazards}

How much is enough? For drugs the answer is usually known. For environmental pollutants the decision is usually influenced by speculation and emotion. Radiation hazards fall between these extremes, with a modest amount of scientific understanding and undertones of anxiety or alarm. The early radiologists underestimated the dangers, but their experience provided a basis for the strict regulations which now limit occupational exposure. More recently there has been concern over the effects of radiation on the population at large, especially from radioactive fallout and diagnostic radiology.

Though radiation has been studied more extensively than any other environmental hazard, the definition of safe levels of exposure for the general public is still a question for informed judgement rather than exact calculation. A new American report ${ }^{1}$ gives a useful summary of present knowledge (and ignorance) on this matter. Noting that the average 
annual personal exposure to natural background radiation amounts to about 120 millirem and that medical radiology adds about 70 millirem (roughly twice the corresponding British figure), the National Council for Radiation Protection and Measurement recommends an upper limit of 170 millirem for the average annual radiation dose incurred by members of the public from all sources other than medical procedures and natural background. At present the only obvious radiation in this category is a modest 5 millirem per year from radioactive fallout. Other sources include luminous watches, shoe-fitting machines, and waste from nuclear establishments.

Firm advice is offered on a number of issues sometimes avoided in official pronouncements. The pregnant radiographer may continue with her work so long as the total radiation dose incurred by the fetus does not exceed 500 millirem-a condition not difficult to fulfil in a well run $x$-ray department. If a radiation worker becomes a patient, radiation incurred during investigation or treatment should be ignored when judging his annual occupational exposure in relation to the prescribed limits.

The council's recommendations have already been attacked ${ }^{2} 3$ on the ground that they are not strict enough and that the process of balancing risks against benefits should be conducted by public debate. While this debate continues, the patient's interest will be best served by the present system of expert consensus reinforced by adequate training and instruction in the assessment and control of hazards among the professions responsible for prescribing and administering radiation.

' National Council on Radiation Protection and Measurements, Basic Radiation Protection Criteria. Washington D.C., 1971.

- Tamplin, A. R., and Gofman, J. W. Population Control Through Nuclear Pollution. Chicago, Nelson-Hall, 1970.

- Boffey, P. M., Science, 1971, 171, 780.

\section{Jejunal Diverticula}

Apart from Meckel's diverticulum, diverticula of the small bowel are less common than elsewhere in the alimentary tract. But they are being diagnosed with greater frequency owing to the use of more routine barium-meal and followthrough examinations. A number of acute and chronic conditions may be due to their presence.

Occasional solitary congenital diverticula may occur, often on the antimesenteric border of the small intestine, composed of all coats of the bowel wall and probably representing partial duplication of the intestine. Acquired diverticula, which are particularly likely to occur in the upper jejunum, are multinle, are found on the mesenteric border, are devoid of muscle, and occur at the points of entry of the blood vessels into the intestine. Diverticulosis of the colon occurs at the points at which the blood vessels enter the gut in association with a thickening of the muscle wall of the intestine, ${ }^{1}$ and it is interesting in this context that J. H. C. Phillips $^{2}$ has noted that musculature of the small intestine is hypertrophic in cases of jejunal diverticulosis.

Jejunal diverticulosis is one of the causes of the blind-loop syndrome. $^{3}$ G. W. Taylor 4 in 1930 noted an example of "per- nicious anaemia" in this condition, and E. Montuschi ${ }^{5}$ in 1949 first reported the association of steatorrhoea with jejunal diverticulosis. A number of scattered reports then followed, but it was J. Badenoch and his colleagues 6 who gave a classical account of the jejunal diverticulosis syndrome, including the development of frank subacute combined degeneration of the cord. G. Watkinson and his colleagues ${ }^{7}$ gave the first example of improvement in both steatorrhoea and the $B_{12}$ level after resection of the affected segment of jejunal diverticulosis. In 1963 W. T. Cooke ${ }^{8}$ and his colleagues from Birmingham, in a masterly review of this topic, showed that in their 33 patients with jejunal diverticula all but four had either symptoms or metabolic disturbances attributable to the presence of the diverticula. A disturbance of vitamin $\mathbf{B}_{12}$ metabolism or absorption was found in 16 patients, and neuropathy was found in 12 . Twenty-three of the patients had abdominal pain and 20 had diarrhoea. One patient had a perforation, and four had intestinal haemorrhage. These authors stressed that their experience was at variance with that of the many earlier workers who claimed that diverticula of the small intestine were not usually associated with symptoms or, if symptoms were present, that the diverticula were merely incidental findings.

E. R. Nobles ${ }^{9}$ has recently published a timely reminder of the serious complications and the difficulties of diagnosis associated with this condition. Over a 10-year period 15 patients underwent resection of the jejunum for serious complications of jejunal diverticulosis at the Baptist Memorial Hospital in Memphis. Five had either acute massive haemorrhage or multiple previous gastrointestinal bleeds; five were operated upon for acute jejunal diverticulitis, of whom three had perforation into the peritoneal cavity and the other two showed localized abscesses round a jejunal diverticulum. Three patients had intestinal obstruction, one due to a large fluid-filled diverticulum which occluded the jejunal lumen and the other two because of adhesions surrounding the diverticulum as the result of old inflammatory disease. The last two patients in the series underwent operation because of intractable abdominal pain, in both cases relieved by the resection.

To the physician, then, jejunal diverticula may present as a cause of vitamin $B_{12}$ deficiency and steatorrhoea. To the surgeon they may be a cause of long-standing abdominal pain or of haemorrhage, perforation, or obstruction. When acute symptoms present, then surgical resection with end-to-end anastomosis is obligatory. Resection may also be curative for those patients with a blind-loop syndrome due to this condition, provided an excessive length of the small intestine is not involved. If the diverticulosis is massive, treatment may have to be restricted to replacement therapy with vitamin $B_{12}$ and intermittent courses of antibiotics.

1 Ellis, H., British Medical Fournal, 1970, 3, 565

2 Phillins, J. H. C., British Fournal of Surgery, 1953, 40, 350

Ellis, H., and Smith, A. D. M., Monographs in the Surgical Sciences, 1967, 4. 193 .

4 Taylor, G. W., New England fournal of Medicine, 1930, 202, 269.

5 Montuschi, E., Proceedings of the Royal Societv of Medicine, 1949, 42, 868.

${ }^{6}$ Badenoch, J. Redford, P. D., and Evans, P. R., Quarterly fournal of Medicine, 1955, 24, 321.

7 Watkinson, G., Feather, D. B., Marson, F. G. W., and Dossett, J. A., British Medical Fournal, 1959, 2. 58.

${ }^{8}$ Cooke, W. T. Cox, E. V., Fone, D. J., Meynell, M. J., and Gaddie, R.,

${ }^{9}$ Nobles, E. R., Archives of Surgery, 1971, 102, 172. 